\title{
An evaluation of continuous subcutaneous infusions across seven NHS acute hospitals: is there potential for 48-hour infusions?
}

\author{
J. Baker ${ }^{1,2^{*}}$ D, A. Dickman ${ }^{1,2}$, S. Mason ${ }^{2}$, M. Bickerstaff ${ }^{3}$, R. Jackson ${ }^{3}$, A. McArdle $^{4}$, I. Lawrence ${ }^{5}$, F. Stephenson ${ }^{5}$,
} N. Paton ${ }^{6}$, J. Kirk ${ }^{7}$, B. Waters ${ }^{8}$ and J. Ellershaw ${ }^{1,2}$

\begin{abstract}
Background: Continuous subcutaneous infusions (CSCls) are commonly used in the United Kingdom as a way of administering medication to patients requiring symptom control when the oral route is compromised. These infusions are typically administered over $24 \mathrm{~h}$ due to currently available safety data. The ability to deliver prescribed medication by CSCl over $48 \mathrm{~h}$ may have numerous benefits in both patient care and health service resource utilisation. This service evaluation aims to identify the frequency at which CSCl prescriptions are altered at NHS Acute Hospitals.

Methods: Pharmacists or members of palliative care teams at seven acute NHS hospitals recorded anonymised prescription data relating to the drug combination(s), doses, diluent and compatibility of CSCls containing two or more drugs on a daily basis for a minimum of 2 days, to a maximum of 7 days.

Results: A total of 1301 prescriptions from 288 patients were recorded across the seven sites, yielding 584 discrete drug combinations. Of the 584 combinations, 91\% $(n=533)$ included an opioid. The 10 most-common $\mathrm{CSCl}$ drug combinations represented $37 \%$ of the combinations recorded. Median duration of an unchanged CSCI prescription across all sites was 2 days.

Conclusion: Data suggests medication delivered by CSCl over $48 \mathrm{~h}$ may be a viable option. Before a clinical feasibility study can be undertaken, a pharmacoeconomic assessment and robust chemical and microbiological stability data will be required, as will the assessment of the perceptions from clinical staff, patients and their families on the acceptability of such a change in practice.
\end{abstract}

Keywords: Palliative therapy, Subcutaneous infusions, CSCl

\section{Background}

With a recent investigation discovering that one-third of all patients in UK District General Hospitals are expected to be in the last year of life [1], and the projected rise in deaths per year from 468,875 (2014) to 561,000

\footnotetext{
* Correspondence: J.baker6@nhs.net

${ }^{1}$ Pharmacy Department, Royal Liverpool University Hospital, Prescot Street, Liverpool L7 8XP, UK

${ }^{2}$ Palliative Care Institute Liverpool, University of Liverpool, Liverpool, UK Full list of author information is available at the end of the article
}

(2035/36) [2] the challenge of providing adequate end-of life care is daunting. Additionally, with the majority of patients expressing a preference to die at home [3, 4], NHS resources will be placed under increasing pressure to meet the needs of chronically ill patients who live, and want to die, in their usual place of residence $[5,6]$.

NHS England has predicted the need to find $£ 22$ billion worth of savings to balance its books by 2020 [7]. As a result, new ways of providing and structuring services are required to optimise care for patients and make

(c) The Author(s). 2020 Open Access This article is licensed under a Creative Commons Attribution 4.0 International License, which permits use, sharing, adaptation, distribution and reproduction in any medium or format, as long as you give appropriate credit to the original author(s) and the source, provide a link to the Creative Commons licence, and indicate if changes were made. The images or other third party material in this article are included in the article's Creative Commons licence, unless indicated otherwise in a credit line to the material. If material is not included in the article's Creative Commons licence and your intended use is not permitted by statutory regulation or exceeds the permitted use, you will need to obtain permission directly from the copyright holder. To view a copy of this licence, visit http://creativecommons.org/licenses/by/4.0/ The Creative Commons Public Domain Dedication waiver (http://creativecommons.org/publicdomain/zero/1.0/) applies to the data made available in this article, unless otherwise stated in a credit line to the data. 
best use of available resources [8]. These pressures, combined with the large number of unfilled medical and nursing posts [9], coupled with the falling number of qualified district nurses (who provide care to patients in their own homes) [10] mean that changes will be required to ensure treatment continues to be provided to the best standard possible.

Continuous subcutaneous infusions (CSCIs) represent an effective method of multiple drug administration in end of life care when the oral route is compromised [11, 12]. Available chemical and microbiological stability data limit the infusion time of a CSCI to a maximum of $24 \mathrm{~h}$ [13]. A pilot study conducted at a large UK teaching hospital revealed that in $72 \%(n=38)$ of cases, no medication changes were made to the CSCI within the first $48 \mathrm{~h}$ of use [14]. This suggests that in certain circumstances (such as patients with stable palliative care needs), there may be an opportunity to deliver medication over $48 \mathrm{~h}$. Such practice may have numerous benefits in both patient care (improving patient autonomy/ freedom, enabling clinicians more time to focus on providing compassionate care) and health service resource utilisation.

An investigation was undertaken to gather data regarding the frequency at which CSCI prescriptions are altered in Acute NHS Trusts to identify if there may be a cohort of patients who could theoretically receive a 48$h$ CSCI. Secondary outcomes included identifying the most frequently prescribed drugs and drug combinations, as well as the assessment of doses prescribed.

\section{Methods}

An open invitation to participate in this evaluation was issued via the UK Palliative Care Pharmacist Network; there were 11 expressions of interest received. Hospital pharmacists or members of palliative care teams at each participating site identified patients who were prescribed CSCIs comprising two or more drugs between July and December 2016.

A nominated pharmacist from each hospital entered the data collected into an electronic database maintained by the Liverpool Cancer Trials Unit. The database was designed to ensure that no patient information was entered. Data relating to a minimum of 50 patients per site was targeted; patients who died or were discharged before $48 \mathrm{~h}$ excluded from the study.

\section{Data analysis}

For each patient identified, the healthcare practitioner recorded the drug combination(s), doses, diluent and compatibility for every CSCI daily, for a minimum of 2 days to a maximum of 7 days. Data collection for each patient ceased after 7 days' continuous treatment, or if the CSCI was discontinued within the 7-day data collection window.

Of primary interest was the number of days that the CSCI ran unchanged. Descriptive analyses were performed, with categorical data presented as counts and continuous data are reported as medians and interquartile ranges. The length of an unchanged CSCI prescription in days was compared, across treatment sites and the most prevalent drug types, using regression modelling techniques which account for different levels of variability between patients and between different treatment sites.

\section{Results}

Of the 11 NHS hospitals who expressed interest, one declined participation, two did not reply to the invitation and one failed to obtain Research and Development approval. All sites were in the North of England (Three hospitals within Merseyside, one hospital each in Lancashire and Greater Manchester with the remainder located in South Yorkshire). At the time of data lock, details from 1301 CSCI prescriptions had been recorded (1362 entries were recorded, but 61 excluded due to erroneous entry), yielding a total of 584 discrete drug combinations. Water for Injections was used as a diluent in 766 cases $(58.9 \%)$, sodium chloride $0.9 \%$ as a diluent in 528 cases $(40.6 \%)$ and no diluent recorded in 7 cases.

\section{Frequency of prescription changes}

An evaluation of the number of days each combination lasted is included in Table 1 for each site. Two hundred eighty-eight patients and 582 combinations are included ( 2 combinations were removed from this analysis due to incomplete records). $45 \%$ (262/582) were changed within 48 h. $38 \%(221 / 582)$ remained stable over 48 h but were changed before $72 \mathrm{~h}$. and $17 \%$ (99/582) were unchanged for longer than 3 days. Over a 5-day week (Monday Friday), $36.7 \%(214 / 582)$ prescriptions remained unchanged for $48 \mathrm{~h}$ or longer. This increased to 55\% (320/ 582) when looking at a seven-day week incorporating a weekend. Overall, median duration of an unchanged CSCI prescription was 2 days. The median duration of an unchanged CSCI prescription at sites 3,5 , and 7 was, however, less than 2 days.

Regression modelling was performed to investigate if there were any differences in the number of days a combination was administered which can be attributed to either the site a patient is treated at or any of the drugs which are administered. Table 2 gives the model estimates for the effects of treatment site. Considering the different treatment sties, Sites 3, 5 and 7 all had significantly negative estimates suggesting that combinations are generally administered for shorter periods of time at these sites compared to site 1 . Site 4 was also close to 
Table 1 Overview of $\mathrm{CSCl}$ prescribing across all sites

\begin{tabular}{|c|c|c|c|c|c|c|c|}
\hline Site & $\begin{array}{l}\text { No. of } \\
\text { Patients }\end{array}$ & $\begin{array}{l}\text { No. of } \mathrm{CSCl} \\
\text { Combinations } \\
\text { recorded }\end{array}$ & $\begin{array}{l}\text { No. of CSCls ran } \\
\text { unchanged for } \\
\text { one day }\end{array}$ & $\begin{array}{l}\text { No. of CSCls that } \\
\text { ran unchanged } \\
\text { for } 2-3 \text { days }\end{array}$ & $\begin{array}{l}\text { No. of CSCls that } \\
\text { ran unchanged } \\
\text { for } 3+\text { days }\end{array}$ & $\begin{array}{l}\text { No. of CSCls that ran for } 2 \text { or more } \\
\text { consecutive days that did not include } \\
\text { Saturday and Sunday }\end{array}$ & $\begin{array}{l}\text { Median duration of } \\
\text { an unchanged CSCl } \\
\text { prescription }\end{array}$ \\
\hline 1 & 83 & 151 & 56 & 57 & 38 & 41 & $2(1,4)$ \\
\hline 2 & 64 & 128 & 48 & 55 & 25 & 28 & $2(1,3)$ \\
\hline 3 & 11 & 20 & 10 & 8 & 2 & 2 & $1.5(1,2.75)$ \\
\hline 4 & 26 & 53 & 20 & 25 & 8 & 8 & $2(1,3)$ \\
\hline 5 & 34 & 71 & 39 & 26 & 6 & 9 & $1(1,2)$ \\
\hline 6 & 21 & 35 & 12 & 13 & 10 & 9 & $2(1,4)$ \\
\hline 7 & 49 & 124 & 77 & 37 & 10 & 9 & $1(1,2)$ \\
\hline
\end{tabular}

statistical significance at the 5\% level. Results suggest that the length of time a CSCI were administered were unaffected by the type of drug that was prescribed.

\section{Drugs used in $\mathrm{CSCls}$}

Table 3 gives the frequency of each drug along with the mean, median, range and IQR of dose prescribed. The results show that the four most common drugs (midazolam hydrochloride, oxycodone hydrochloride, levomepromazine hydrochloride, morphine sulphate) account for 983/1605 (61\%) of all drugs prescribed.

\section{Drug combinations used}

Of the 584 drug combinations recorded across the seven sites, 128 unique drug combinations were identified. The number of drugs in a combination were distributed as: 2 drugs 251/584 (43\%), 3 drugs 232/584 (40\%), 4 drugs 98 (17\%) and 5 drugs $3(<1 \%)$. A list of the top 31 drug combinations prescribed is included in Table 4.

An opioid was included in $91 \%(n=533)$ of cases with 5 of the 6 most common combinations comprising morphine sulphate. The six most common combinations all comprised midazolam hydrochloride. Twenty-four hour laboratory-tested chemical compatibility and stability data at clinically relevant doses were available for 24 of the top-31 drug combinations [13, 15-25], while $48 \mathrm{~h}$

Table 2 Results of the mixed log-logistic model to evaluate factors associated with administration time

\begin{tabular}{lllll}
\hline & Estimate & Standard Error & z value & $\operatorname{Pr}(>|z|)$ \\
\hline Intercept & 1.012 & 0.098 & 10.290 & 0.000 \\
Site 1 & - & - & - & - \\
Site 2 & -0.118 & 0.090 & -1.316 & 0.188 \\
Site 3 & $\mathbf{- 0 . 3 7 2}$ & $\mathbf{0 . 1 7 3}$ & $\mathbf{- 2 . 1 5 2}$ & $\mathbf{0 . 0 3 1}$ \\
Site 4 & -0.235 & 0.123 & -1.907 & 0.057 \\
Site 5 & $\mathbf{- 0 . 4 0 7}$ & $\mathbf{0 . 1 1 3}$ & $\mathbf{- 3 . 6 0 7}$ & $\mathbf{0 . 0 0 0}$ \\
Site 6 & 0.003 & 0.135 & 0.022 & 0.982 \\
Site 7 & $\mathbf{- 0 . 4 3 7}$ & $\mathbf{0 . 0 9 6}$ & $\mathbf{- 4 . 5 4 9}$ & $\mathbf{0 . 0 0 0}$ \\
\hline
\end{tabular}

compatibility and stability data were available for 4 of the top-31 drug combinations [16, 22-25].

\section{Mean morphine equivalent dose}

Table 5 gives the mean daily dose of all opioids prescribed and converts to the equivalent morphine dose as per current national guidance [27].

\section{Discussion}

To our knowledge, this investigation represents the first analysis of CSCI prescribing trends over a continuous period of up to 7 days in the United Kingdom. CSCIs were unchanged following two or more consecutive days in $55 \%(n=320)$ of cases, compared to $72 \%(n=38)$ in the pilot study [14]. Of the 320 CSCIs in which drugs or dosages did not change for periods greater than 2 days, $33 \%$ included the days Saturday and Sunday, which are traditionally less well staffed in NHS establishments. Despite this, there is a potential population in whom a 48-h CSCI infusion may be practicable both in terms of decreasing the frequency of interventions administered to the patient and optimising the utilisation of a healthcare professional's time.

As demonstrated by the most recent survey of national CSCI prescribing practice, oxycodone was the most commonly prescribed opioid identified by this study [28]. This is despite current national guidance recommending the use of an opioid with the lowest acquisition cost first-line (currently morphine sulphate) [29]. However, morphine sulphate is still widely utilised as shown by its inclusion in five of the six most frequently prescribed drug combinations.

The top two most-common drug combinations correspond with the findings of the most-recent survey of national prescribing practice. The third most-common drug combination included the "four core" drugs needed for quality care of the dying patient (morphine, midazolam, levomepromazine and glycopyrronium) [30]. The frequency of this prescription, and that its use was restricted to one site (site 7) is anomalous and reasons for this need investigation in future work. From the clinical 
Table 3 Frequency and dose range of drugs prescribed in $\mathrm{CSCl}$ combinations recorded

\begin{tabular}{|c|c|c|c|c|c|c|}
\hline Drug & $\begin{array}{l}\text { UK Licensing status for SC } \\
\text { Infusion }\end{array}$ & Frequency & $\begin{array}{l}\text { Mean dose } \\
(\mathrm{mg})\end{array}$ & $\begin{array}{l}\text { Median dose } \\
(\mathrm{mg})\end{array}$ & $\begin{array}{l}\text { Dose range } \\
(\mathrm{mg})\end{array}$ & IQR (mg) \\
\hline Midazolam hydrochloride & Unlicensed & 309 & 11.63 & 10 & $(2.5,60)$ & $(5,12.5)$ \\
\hline Oxycodone hydrochloride & Licensed & 230 & 21.09 & 15 & $(2.5,150)$ & $(7.5,25)$ \\
\hline Levomepromazine hydrochloride & Licensed & 225 & 13.77 & 6.25 & $(6.2,150)$ & $(6.2,12.5)$ \\
\hline Morphine sulphate & Unlicensed & 219 & 19.14 & 10 & $(2.5,190)$ & $(7.5,20)$ \\
\hline Glycopyrronium bromide & Unlicensed & 120 & 1.35 & 1.2 & $(0.4,2.4)$ & $(0.6,2)$ \\
\hline Hyoscine butylbromide & Unlicensed & 105 & 89.9 & 60 & $(20,240)$ & $(60,120)$ \\
\hline Alfentanil hydrochloride & Unlicensed & 82 & 1.8 & 1.12 & $(0.2,12.5)$ & $(0.6,2)$ \\
\hline Haloperidol lactate & Unlicensed & 66 & 2.7 & 2.5 & $(0.5,10)$ & $(1.5,3)$ \\
\hline Cyclizine lactate & Unlicensed & 62 & 150 & 150 & $(150,150)$ & $(150,150)$ \\
\hline Clonazepam & Unlicensed & 57 & 1.18 & 1 & $(0.1,6)$ & $(0.2,2)$ \\
\hline Metoclopramide hydrochloride & Unlicensed & 46 & 36.52 & 30 & $(15,90)$ & $(30,40)$ \\
\hline Ondansetron hydrochloride & Unlicensed & 33 & 15.52 & 12 & $(8,36)$ & $(12,16)$ \\
\hline Ketamine hydrochloride & Unlicensed & 13 & 171.15 & 150 & $(100,300)$ & $(125,200)$ \\
\hline Octreotide acetate & Unlicensed & 11 & 0.65 & 0.6 & $(0.6,0.9)$ & $(0.6,0.6)$ \\
\hline Hyoscine hydrobromide & Unlicensed & 11 & 1.47 & 1.2 & $(1.2,2.4)$ & $(1.2,1.5)$ \\
\hline $\begin{array}{l}\text { Dexamethasone sodium } \\
\text { phosphate }\end{array}$ & Unlicensed & 10 & 0.98 & 1 & $(1,1)$ & $(1,1)$ \\
\hline Levetiracetam & Unlicensed & 2 & 375 & 375 & $(250,500)$ & $\begin{array}{l}(312.5 \\
437.5)\end{array}$ \\
\hline Furosemide & Unlicensed & 2 & 200 & 200 & $(200,200)$ & $(200,200)$ \\
\hline Diamorphine hydrochloride & Licensed & 2 & 7.5 & 7.5 & $(5,10)$ & $(6.2,8.8)$ \\
\hline
\end{tabular}

experience of the authors, such patterns can occur with clinicians that have limited experience of prescribing CSCI's. This was also evidenced by frequent, small, incremental dose changes being made to a patient's CSCI prescription. The fourth most-common combination (morphine + midazolam + levomepromazine) as found by this investigation was sixth most common in the previously completed evaluation.

Of the top-31 drug combinations, only 4 combinations have 48-h chemical compatibility and stability data. However, as 48-h infusions may present a greater patient infection risk than 24-h infusions, risk/benefit analysis of ward based CSCI compounding versus pharmacy based aseptic preparation, or the inclusion of an in-line antimicrobial filter, [31] will be required prior to adoption into clinical practice.

While there is potentially an alternative to CSCI prescribing (i.e. utilizing agents that possess long plasma half-lives (e.g. levomepromazine) or alternative routes of administration (e.g. transdermal)) these approaches may not be considered appropriate for several reasons. Firstly, the administration of large subcutaneous doses of an agent may result in increased incidents of adverse effects and injection site irritation. Additionally, the duration of action of most if not all drugs commonly administered by CSCI in palliative care does not exceed $24 \mathrm{~h}$. Therefore, a daily visit will still be required.

Secondly, should a dose need adjusting because, for example, the patient's condition changed, with a CSCI the infusion can be stopped, and doses changed accordingly. In the case of administration of a high dose of a long-acting drug, or a transdermal preparation, the effect will persist for a significantly longer duration.

For these reasons, 48-h CSCIs may be preferred due to the provision of a consistent, drug plasma level.

\section{Strengths and limitations of this investigation}

This evaluation was the first of its kind, and as such has identified opportunities for further research into the utility of extended-duration CSCIs. The adoption of increased infusion duration may have potential to benefit the utilisation of NHS resources and ultimately patient care.

Obtaining local Research and Development approvals at some sites took unexpectedly longer than planned and as a result limited the volume of data collected. We were unable to ascertain from all participating sites whether patients included in the evaluation received a daily review (and whether such a review was performed by a specialist or generalist). Additionally, information as 
Table 4 Top 31 combinations present in 1301 recorded CSCI prescriptions

\begin{tabular}{|c|c|c|c|c|}
\hline Drug 1 & Drug 2 & Drug 3 & Drug 4 & Frequency \\
\hline Morphine sulphate & Midazolam hydrochloride & & & $40^{\mathrm{a}}$ \\
\hline Oxycodone hydrochloride & Midazolam hydrochloride & & & 35 \\
\hline Morphine sulphate & Glycopyrronium bromide & Levomepromazine hydrochloride & Midazolam hydrochloride & 25 \\
\hline Morphine sulphate & Levomepromazine hydrochloride & Midazolam hydrochloride & & 22 \\
\hline Oxycodone hydrochloride & Hyoscine butylbromide & Midazolam hydrochloride & & 21 \\
\hline Morphine sulphate & Glycopyrronium bromide & Midazolam hydrochloride & & 19 \\
\hline Oxycodone hydrochloride & Levomepromazine hydrochloride & & & 14 \\
\hline Alfentanil hydrochloride & Midazolam hydrochloride & & & $13^{\mathrm{a}}$ \\
\hline Oxycodone hydrochloride & Glycopyrronium bromide & Levomepromazine hydrochloride & Midazolam hydrochloride & 13 \\
\hline Morphine sulphate & Levomepromazine hydrochloride & & & $13^{\mathrm{a}}$ \\
\hline Oxycodone hydrochloride & Levomepromazine hydrochloride & Midazolam hydrochloride & & 13 \\
\hline Oxycodone hydrochloride & Metoclopramide hydrochloride & & & 10 \\
\hline Oxycodone hydrochloride & Clonazepam & Haloperidol lactate & & 10 \\
\hline Oxycodone hydrochloride & Clonazepam & & & 10 \\
\hline Oxycodone hydrochloride & Cyclizine lactate & & & 10 \\
\hline Alfentanil hydrochloride & Glycopyrronium bromide & Levomepromazine hydrochloride & Midazolam hydrochloride & 10 \\
\hline Morphine sulphate & Cyclizine lactate & & & 9 \\
\hline Oxycodone hydrochloride & Hyoscine butylbromide & Haloperidol lactate & & 8 \\
\hline Morphine sulphate & Hyoscine butylbromide & Midazolam hydrochloride & & 8 \\
\hline Morphine sulphate & Metoclopramide hydrochloride & & & $7^{\mathrm{a}}$ \\
\hline Oxycodone hydrochloride & Haloperidol lactate & Midazolam hydrochloride & & 7 \\
\hline Alfentanil hydrochloride & Levomepromazine hydrochloride & Midazolam hydrochloride & & 7 \\
\hline Hyoscine butylbromide & Levomepromazine hydrochloride & & & 7 \\
\hline Oxycodone hydrochloride & Glycopyrronium bromide & Midazolam hydrochloride & & 7 \\
\hline Glycopyrronium bromide & Midazolam hydrochloride & & & 7 \\
\hline Oxycodone hydrochloride & Cyclizine lactate & Haloperidol lactate & & 6 \\
\hline Alfentanil hydrochloride & Glycopyrronium bromide & Midazolam hydrochloride & & 6 \\
\hline Alfentanil hydrochloride & Hyoscine butylbromide & Levomepromazine hydrochloride & Midazolam hydrochloride & 5 \\
\hline Morphine sulphate & Hyoscine butylbromide & Levomepromazine hydrochloride & Midazolam hydrochloride & 5 \\
\hline Oxycodone hydrochloride & Hyoscine butylbromide & Levomepromazine hydrochloride & Midazolam hydrochloride & 5 \\
\hline Oxycodone hydrochloride & Hyoscine butylbromide & Levomepromazine hydrochloride & & 5 \\
\hline
\end{tabular}

${ }^{a}$ indicates combinations known to have been analysed for 48 -h compatibility and stability at clinically relevant doses

to why the dose remained unchanged following review by a member of the palliative care team each day was not recorded. In clinical practice, however, nursing staff are required to monitor the patient's symptoms, infusion device and administration set at frequent intervals throughout the 24-h infusion period and request a clinical review if the patient's condition appears to change significantly. As this evaluation aimed to provide a "snapshot" of prescribing practice at the participating organisations, patient demographics were not collected.

Table 5 Mean morphine equivalent daily dose for prescribed opioids

\begin{tabular}{lll}
\hline Opioid & Mean parenteral daily dose $(\mathrm{mg})$ & Mean oral morphine equivalent dose $(\mathrm{mg})$ \\
\hline Alfentanil hydrochloride & 1.8 & 54 \\
Diamorphine hydrochloride & 7.5 & 22.5 \\
Morphine sulphate & 19.14 & 38.28 \\
Oxycodone hydrochloride & 21.09 & 84.36
\end{tabular}


Should a national registry be developed, these details would be captured and allow identification of specific patient groups more likely to receive benefit from this intervention.

A further limitation of this investigation was that all acute hospitals that took part were based in the North of England, with a particular focus on the North-West and only performed within an acute hospital setting.

\section{Conclusions}

This evaluation identified patients receiving treatment by a CSCI who did not require changes to drugs and/or dosages for at least $48 \mathrm{~h}$. Thus, there may be a cohort of patients in whom there is the potential to extend the infusion period from the current standard of $24 \mathrm{~h}$ to $48 \mathrm{~h}$.

\section{Future implications for research}

To confirm this articles findings and explore populations in which such an intervention may be beneficial, a more robust assessment of practice is required. For example, a future study should also investigate the prescribing of CSCIs in primary care to determine if this follows a similar pattern to that observed in this evaluation. To this end, the creation of a national registry of both primary and secondary care CSCI prescribing may assist in helping to explore the points previously mentioned and identify suitable patient cohorts.

Prior to the undertaking of any clinical feasibility study, pharmacoeconomic analysis and robust chemical and microbiology stability data would be required for all commonly encountered drug combinations. Ideally, such a study would incorporate assessment of the perceptions of clinical staff, patients and their families on the acceptability of such a fundamental change in practice.

\section{Abbreviations}

CSCl: Continuous subcutaneous infusion; IQR: Inter-quartile range: mg: Milligrams; NHS: National Health Service; SC: Subcutaneous; UK: United Kingdom

\section{Acknowledgements}

Not applicable.

\section{Authors' contributions \\ $A D, S M$ and JE conceptualised the investigation and obtained the required funding. AD, JB, AM, IL, FS, NP, JK and BW collected prescription data at their respective sites and entered the anonymised data onto the electronic database. MB oversaw the management of the electronic database. RJ performed statistical analysis. JB authored the draft manuscript and subsequent revisions with editorial advice provided by AD, SM and JE. All authors have read and approved the manuscript.}

\section{Funding}

This investigation was performed with funding from NHS Liverpool CCG. The funders had no role in study design, data collection and analysis, decision to publish, or preparation of the manuscript.

\section{Availability of data and materials}

The datasets used and/or analysed during the current study are available from the corresponding author on reasonable request.
Ethics approval and consent to participate

As this study was classified by the Health Research Authority as a service evaluation, ethical approval was not required.

\section{Consent for publication}

Not applicable.

\section{Competing interests}

The authors declare that they have no competing interests.

\section{Author details}

${ }^{1}$ Pharmacy Department, Royal Liverpool University Hospital, Prescot Street, Liverpool L7 8XP, UK. 'Palliative Care Institute Liverpool, University of Liverpool, Liverpool, UK. ${ }^{3}$ Liverpool Clinical Trials Unit, University of Liverpool, Liverpool, UK. ${ }^{4}$ Pharmacy Department, Wirral University Teaching Hospital NHS Foundation Trust, Wirral, UK. ${ }^{5}$ Pharmacy Department, Sheffield Teaching Hospitals NHS Foundation Trust, Sheffield, UK. ${ }^{6}$ Pharmacy Department, The Christie NHS Foundation Trust, Manchester, UK. ${ }^{7}$ Pharmacy Department, St Helens and Knowsley Teaching Hospitals NHS Trust, Prescot, UK. ${ }^{8}$ Pharmacy Department, Blackpool Teaching Hospitals NHS Foundation Trust, Blackpool, UK.

Received: 26 March 2019 Accepted: 1 July 2020

Published online: 07 July 2020

\section{References}

1. Clark D, Armstrong M, Allan A, Graham F, Carnon A, Isles C. Imminence of death among hospital inpatients: prevalent cohort study. Palliat Med. 2014; 28:474-9.

2. Office for National Statistics. 2014-based National Population Projection: Principal Projection - England Summary. London: ONS; 2015.

3. Gomes B, Calanzani N, Gysels M, Hall S, Higginson IJ. Heterogeneity and changes in preferences for dying at home: a systematic review. BMC Palliative Care. 2013;12(1):7.

4. Wood C, Salter J. A time and a place: what people want at the end of life. Sue Ryder/Demos. 2013. https://www.scie-socialcareonline.org.uk/a-timeand-a-place-what-people-want-at-the-end-of-life/r/a11G00000018A5DIAU.

5. Davis D, Brayne C. Ageing, health, and social care: reframing the discussion. Lancet. 9979:385:1699-700.

6. Gomez-Batiste X, Martinez-Munoz M, Blay C, Amblas J, Vila L, Costa X, Espaulella J, Espinosa J, Constante C, Mitchell GK. Prevalence and characteristics of patients with advanced chronic conditions in need of palliative care in the general population: a cross-sectional study. Palliat Med. 2014:28(4):302-11

7. NHS England: Five Year Forward View. 2014

8. Lord Carter of Coles: 'Operational productivity and performance in English NHS acute hospitals: Unwarranted variations'. An independent report for the Department of Health. 2016.

9. Thousands of NHS nursing and doctor posts lie vacant. http://www.bbc.co. uk/news/health-35667939. Accessed 2 Dec 2019.

10. Moore J. Patients hardest hit by district nursing recruitment crisis. Nurs Stand. 2014;28(43):34-5.

11. Adam J. ABC of palliative care: the last 48 hours. BMJ. 1997;315(7122): $1600-3$.

12. Ellershaw J, Ward C. Care of the dying patient: the last hours or days of life. BMJ. 2003;326(7379):30-4.

13. Dickman A, Roberts E, Bickerstaff M, Jackson R, Ellershaw J. Chemical compatibility/stability of commonly used drug combinations administered by continuous subcutaneous infusions for end of life care. Support Care Cancer. 2015;23:S202.

14. Dickman A, Scott J. Evaluating the frequency of medication adjustments to continuous subcutaneous infusions in palliative care: Is there evidence to support 48-hourly infusions? in. Copenhagen: Multinational Association of Supportive Care in Cancer (MASCC); 2015.

15. Al-Tannak NF, Cable CG, McArthur DA, Watson DG. A stability indicating assay for a combination of morphine sulphate with levomepromazine hydrochloride used in palliative care. J Clin Pharm Ther. 2012;37(1):71-3.

16. Chandler SW. Trissel LA, Weinstein SM. Combined administration of opioids with selected drugs to manage pain and other cancer symptoms initial safety screening for compatibility. J Pain Symptom Manag. 1996;12(3):168-71. 
17. Dickman A, Hunter S. Physical Compatibility of Oxycodone Injection with Supportive Drugs in Palliative Care. Aachen: Poster presented at: 9th Congress of the European Association for Palliative Care; 2005.

18. Dickman A, Kean H, Ellershaw J, Rigge D, Weir P. Chemical Compatibility/ Stability of Alfentanil with Commonly Used Supportive Drug Combinations Adminstered by Subcutaneous Infusions for End of Life Care. Lisbon: Poster presented at: 12th World Research Congress of the European Association for Palliative Care; 2011.

19. Dickman A, Kean H, Rigge D, Weir P, Ellershaw J. Chemical compatibility/ stability of commonly used drug combinations administered by continuous subcutaneous infusions for end of life care. Palliat Med. 2010;24:S141.

20. Gardiner PR. Compatibility of an injectable oxycodone formulation with typical diluents, syringes, tubings, infusion bags and drugs for potential coadministration. Hosp Pharm. 2003;10:354-61.

21. Hines S, Pleasance S. Compatibility of an injectable high strength oxycodone formulation with typical diluents, syringes, tubings, infusion bags and drugs for potential co-administration. EJHP Pract. 2009;15(5):32-8.

22. LeBelle MJ, Savard C, Gagnon A. Compatibility of morphine and midazolam or haloperidol in parenteral admixtures. Can J Hosp Pharm. 1995:48(3):155-60.

23. Mehta AC, Kay EA. Storage time can now be extended. Pharm Pract. 1997;7: $305-8$.

24. Nixon AR, O'Hare MCB. The stability of morphine sulphate and metoclopramide hydrochloride in various delivery presentations. Pharm J. 1995;254:153-5.

25. Storey P, Hill HH, Louis RHS, Tarver EE. Subcutaneous infusions for control of cancer symptoms. J Pain Symptom Manag. 1990;5(1):33-41.

26. Raff M, Belbachir A, El-Tallawy S, Ho KY, Nagtalon E, Salti A, Seo JH, Tantri AR, Wang $H$, Wang $T$, et al. Intravenous oxycodone versus other intravenous strong opioids for acute postoperative pain control: a systematic review of randomized controlled trials. Pain Ther. 2019;8(1):19-39.

27. Twycross R, Wilcock A, Howard P. Palliative care formulary. 5th ed. Nottingham: Palliativedrugs.com Ltd; 2014.

28. Dickman A, Bickerstaff M, Jackson R, Schneider J, Mason S, Ellershaw J. Identification of drug combinations administered by continuous subcutaneous infusion that require analysis for compatibility and stability. BMC Palliative Care. 2017:16(1):22

29. National Institute for Health and Care Excellence (NICE). Palliative care for adults: strong opioids for pain relief (CG140). London: Edited by Excellence NIfHaC; 2012. p. 9.

30. Lindqvist O, Lundquist G, Dickman A, Bukki J, Lunder U, Hagelin CL, Rasmussen BH, Sauter S, Tishelman C, Furst CJ. Four essential drugs needed for quality care of the dying: a Delphi-study based international expert consensus opinion. J Palliat Med. 2013;16(1):38-43.

31. McKinnon BT, Avis KE. Membrane filtration of pharmaceutical solutions. Am J Hosp Pharm. 1993;50(9):1921-36.

\section{Publisher's Note}

Springer Nature remains neutral with regard to jurisdictional claims in published maps and institutional affiliations.

Ready to submit your research? Choose BMC and benefit from:

- fast, convenient online submission

- thorough peer review by experienced researchers in your field

- rapid publication on acceptance

- support for research data, including large and complex data types

- gold Open Access which fosters wider collaboration and increased citations

- maximum visibility for your research: over $100 \mathrm{M}$ website views per year

At $\mathrm{BMC}$, research is always in progress.

Learn more biomedcentral.com/submissions 